\title{
Erratum to: Neuro-fuzzy modeling of the convection heat transfer coefficient for the nanofluid
}

\author{
H. Salehi ${ }^{1} \cdot$ S. Zeinali-Heris ${ }^{1} \cdot$ M. Esfandyari $^{2} \cdot$ M. Koolivand ${ }^{3}$
}

Published online: 16 April 2015

(C) Springer-Verlag Berlin Heidelberg 2015

Erratum to: Heat Mass Transfer (2013) 49:575-583

DOI 10.1007/s00231-012-1104-9

In the original publication, the article title has been incorrectly published with typo error. The correct article title should read as "Neuro-fuzzy modeling of the convection heat transfer coefficient for the nanofluid".

The online version of the original article can be found under doi:10.1007/s00231-012-1104-9.

H. Salehi

h.salehi1363@gmail.com

1 Department of Chemical Engineering, Faculty of Engineering, Heat Pipe and Nanofluid Research Center, Ferdowsi University of Mashhad, Mashhad, Iran

2 Department of Chemical Engineering, Faculty of Engineering, Ferdowsi University of Mashhad, Mashhad, Iran

3 Petroleum Department, National Iranian South Oil Field Company, Ahwaz, Iran 